\title{
O PROJETO PARA COMBATER A VIOLÊNCIA DOMÉSTICA CONTRA A MULHER DA UNIVERSIDADE DE SANTA CRUZ - UNISC/RS ENQUANTO PRÁTICA DE EXTENSÃO UNIVERSITÁRIA NA CONSTRUÇÃO DO CONHECIMENTO JURÍDICO E PARA A FORMAÇÃO HUMANISTA DOS ACADÊMICOS
}

\section{Caroline Fockink Ritt * Eduardo Ritt ${ }^{* *}$}

\begin{abstract}
RESUMO: O objetivo do presente estudo é demonstrar a importância de projetos de extensão universitária na formação acadêmica dos alunos do Direito. O método de abordagem é o dedutivo e o de interpretação o método sociológico. Como resultados: os alunos bolsistas participantes adquirem formação acadêmica mais completa, conjugando os ensinamentos teóricos, adquiridos no curso de Direito, com as situações práticas, apresentadas pelas vítimas de violência doméstica. O contato com a realidade e a possibilidade de atuação trazem para os acadêmicos bolsistas uma melhor compreensão dos problemas sociais, da violência, maior interação comunitária resultando também em uma formação acadêmica mais humanista.
\end{abstract}

Palavras-chave: extensão universitária, ensino humanista; Lei Maria da Penha; violência doméstica.

\section{THE PROJECT TO COMBAT DOMESTIC VIOLENCE AGAINST WOMEN FROM THE UNIVERSITY OF SANTA CRUZ - UNISC / RS AS A PRACTICE OF UNIVERSITY EXTENSION IN THE CONSTRUCTION OF LEGAL KNOWLEDGE AND FOR THE HUMANIST TRAINING OF ACADEMIC}

\begin{abstract}
The purpose of this study is to demonstrate the importance of university extension projects in the academic training of Law course students. The method of approach is the deductive and the method of interpretation is the sociological method. As a result: the participating scholarship students acquire more complete academic training, combining the theoretical teachings, acquired in the Law course, with the practical situations presented by the victims of domestic violence. The contact with reality and the possibility of acting, bring scholarship scholars to a better understanding of social problems, violence, greater community interaction resulting in a more humanistic academic formation.
\end{abstract}

\footnotetext{
"Caroline Fockink Ritt. É doutora em Direito, pós doutoranda em Direitos Fundamentais pela PUC, no RS, professora de Direito Penal e Criminologia no curso de Direito da Universidade de Santa Cruz do Sul - UNISC. Coordenadora do Projeto de Extensão: "Enfrentamento da violência doméstica e familiar-Direitos e garantias legais da Mulher agredida", que é desenvolvido pela Universidade de Santa Cruz - UNISC, na cidade de Montenegro, em parceria com a Delegacia Especializada no Atendimento à Mulher - DEAM Montenegro. Email: carolinefritt@gmail.com.
}

** Eduardo Ritt. Promotor de Justiça. Mestre em Direito pela Universidade de Santa Cruz do Sul/RS (UNISC). Promotor de Justiça em Santa Cruz do Sul/RS. Professor de Processo penal na referida universidade. Coordena o projeto de extensão: Enfrentamento da Violência Doméstica e Familiar: Direitos da Mulher Agredida, em Santa Cruz do Sul/RS. E-mail: eduardoritt@mprs.mp.br 
Key words: University extension, humanistic teaching; Maria da Penha Law; domestic violence.

\section{INTRODUÇÃO}

O presente artigo científico tem como objetivo principal demonstrar a importância de projetos de extensão universitária na formação acadêmica dos alunos do Direito. Como problema de pesquisa, temos a seguinte indagação: Qual a importância da extensão universitária para a formação dos acadêmicos do Direito? O presente artigo desenvolve-se três tópicos que são: (1) abordar a violência doméstica praticada contra a mulher; (2) demonstrar que a prevenção e a punição da violência doméstica praticada contra a mulher pode ser considerado um direito fundamental, (3) analisar, sem a possibilidade de esgotar o assunto, legislação constitucional que trata este assunto, principalmente a Lei Maria da Penha, considerada a mais importante no combate à violência doméstica praticada contra a mulher; (4) descrever o projeto de extensão que é desenvolvido pela UNISC/RS. E, (5) encaminhando-se para as considerações finais, o de demonstrar a importância da extensão universitária para uma formação prática e humanista dos acadêmicos do curso de Direito. $\mathrm{O}$ método de abordagem é o dedutivo: parte-se da demonstração de que as práticas de extensão enriquecem o aprendizado dos alunos do Curso do Direito pelo fato de que eles possuem a oportunidade, por meio da extensão, de conjugar os ensinamentos teóricos adquiridos no curso de Direito com situações práticas que lhes são apresentadas.

Aborda-se, no presente, para fins de exemplo, a análise do projeto de extensão, que visa a combater a violência doméstica praticado contra a mulher, que é desenvolvido pela UNISC/RS, denominado de: Enfrentamento da violência doméstica e familiar - Direitos e garantias legais da Mulher agredida. Demonstra-se que os alunos bolsistas que participam do referido projeto, adquirem uma formação acadêmica mais completa, por terem a oportunidade de conjugar os ensinamentos teóricos, adquiridos no curso de Direito, com as situações práticas, apresentadas pelas vítimas de violência doméstica. O contato com esta realidade social, a possibilidade de atuação, aconselhamentos e encaminhamentos, com relação a estas mulheres traz para os acadêmicos do curso de Direito, que são bolsistas no projeto de extensão, uma melhor compreensão dos problemas sociais, da realidade de 
violência doméstica e familiar praticada contra a mulher e maior interação comunitária e uma formação acadêmica mais humanista.

\section{CONSIDERAÇÕES SOBRE A VIOLÊNCIA DOMÉSTICA PRATICADA CONTRA}

\section{A MULHER}

Violência vem do latim violentia, que significa caráter violento ou bravio. Para Cavalcanti (2007, p. 29), o termo violare significa tratar com violência, profanar, transgredir. Esses termos devem ser referidos a vis, que significa a força em ação, o recurso de um corpo para exercer a sua força e, portanto, a potência, o valor, ou seja, a força vital. Violência que é composto por vis, que em latim significa força, sugere a ideia de vigor, potência, impulso. Também traz a ideia de excesso e de destemor. Então, mais do que uma simples força, violência pode ser conceituada como o próprio abuso da força.

É, pois, o ato de brutalidade, constrangimento, abuso, proibição, desrespeito, discriminação, imposição, invasão, ofensa, agressão física, psíquica, moral ou patrimonial contra alguém, caracterizando relações que se baseiam na ofensa e na intimidação pelo medo e pelo terror.

Arendt (1994, p. 32) traz a devida observação sobre as discussões a respeito do fenômeno da violência e do poder. Então é possível perceber que existe um consenso entre os teóricos da política, tanto da esquerda como da direita, no sentido de que a violência é tão somente a mais flagrante manifestação de poder.

A violência cometida contra a mulher é um fenômeno histórico que dura milênios, pois a mulher era tida como um ser sem expressão, uma pessoa que não possuía vontade própria dentro do ambiente familiar. Ela não podia sequer expor o seu pensamento e era obrigada a acatar ordens que, primeiramente, vinham de seu pai e, após o casamento, de seu marido (MELLO, 2007, p. 03).

Historicamente, Soares (1999, p. 25) observa que, nos Estados Unidos, apesar de muitos esforços ocorridos durante o séc. XIX, com o objetivo de diminuir as formas e a intensidade dos castigos físicos que eram impostos legalmente às mulheres por seus maridos, foi somente em 1871, e apenas nos estados do Alabama e Massachussetts, que foi oficialmente extinto o direito de os homens baterem nas mulheres, mas mesmo assim, não havia previsão de punição para os que continuassem a cometer essa violência. 
Complementa Hirigoyen (2006, p. 10-11) que foi somente após a década de 1970, com as iniciativas das feministas, que se começou a fazer um estudo do impacto da violência conjugal entre as mulheres. Até então se hesitava em intervir, sob pretexto de que se tratava de "assunto privado". Observa-se que era um verdadeiro flagelo social. Os números, que só levam em conta as violências físicas que chegam ao Judiciário, são assustadores. Na França, por exemplo: estatísticas parciais do Ministério do Interior (que excluem Paris e a região parisiense) registram, a cada quinze dias, três homicídios de mulheres, assassinadas por seu cônjuge. O fenômeno é de tal monta que alguns chegam a falar em "terrorismo de gênero", e por isso a maior parte das pesquisas de opinião especificamente sobre a violência conjugal foi realizada a pedido dos Ministérios dos Direitos das Mulheres ou da Paridade e Igualdade Profissional, por pressão das ONGs de mulheres. Esse problema de saúde mental extremamente destrutivo raramente é debatido e, apesar de suas graves consequências sobre a saúde das vítimas, só em caráter facultativo é ensinado aos futuros médicos.

Cometida nas suas mais variadas formas de manifestação, afeta a saúde, a vida: produz enfermidades, danos psicológicos e também pode provocar a morte. Tem como objetivo causar dano a um organismo vivo, ou seja, é qualquer comportamento que tem como objetivo o de causar dano a outrem (LINTZ, 1987, p. 27).

Para Dias (2007, p. 32), a violência doméstica está ligada, frequentemente, tanto ao uso da força física, psicológica ou intelectual, no sentido de obrigar outra pessoa a fazer algo que não quer. Ou seja, impedir que ela manifeste sua vontade, tolhendo sua liberdade, é considerada uma forma de violação dos direitos essenciais do ser humano.

Nas relações familiares violentas, Cavalcanti (2007, p. 29) observa a presença da força bruta já que os agressores se utilizam da relação de poder e da força física para subjugar as vítimas e mantê-las sob o seu jugo das mais variadas formas de violência. Uma simples divergência de opinião ou uma discussão de somenos importância pode se transformar em agressões verbais e físicas, que são capazes de consequências danosas para toda a família. Nesses conflitos, a palavra, o diálogo e a argumentação dão lugar aos maus tratos, utilizados cotidianamente como forma de solucioná-los.

Especificamente à violência contra a mulher e à violência doméstica, há uma explicação cultural para a sua grande ocorrência no Brasil. Ela não está ligada somente à lógica da pobreza, ou desigualdade social e cultural, mas está ligada diretamente ao preconceito, à discriminação e ao abuso de poder que possui o agressor com relação à sua 
vítima. A mulher, em razão de suas peculiaridades, compleição física, idade, e, principalmente, dependência econômica, está em uma situação de absoluta vulnerabilidade social.

Sabadell (2005, p. 258) destaca que a Organização Mundial da Saúde, em seus estudos, indica que quase a metade das mulheres vítimas de homicídio são assassinadas pelo marido ou namorado, tanto pelo ex como também pelo atual. Da mesma forma, pesquisa realizada pela Anistia Internacional, em cinquenta países, trouxe dados que revelaram que uma em cada três mulheres foi vítima de violência doméstica, como também obrigada a manter relações sexuais ou submetida a outros tipos de violência. Por exemplo: em 2005 a Organização Mundial da Saúde elaborou um estudo sobre a saúde da mulher e a violência doméstica em dez países, incluindo o Brasil, e constatou que, apesar dos compromissos internacionais assumidos, não ocorreram mudanças significativas no que se refere à prática deste tipo de violência.

Dados publicizados em um levantamento do Datafolha feito em fevereiro de 2019, encomendada pela ONG Fórum Brasileiro de Segurança Pública (FBSP) para avaliar o impacto da violência contra as mulheres no Brasil, trouxe que nos últimos 12 meses, 1,6 milhão de mulheres foram espancadas ou sofreram tentativa de estrangulamento no Brasil, enquanto 22 milhões $(37,1 \%)$ de brasileiras passaram por algum tipo de assédio. Dentro de casa, a situação não foi necessariamente melhor. Entre os casos de violência, $42 \%$ ocorreram no ambiente doméstico. Após sofrer uma violência, mais da metade das mulheres (52\%) não denunciou o agressor ou procurou ajuda (FRANCO, 2019, <https://www.bbc.com>).

Devido à relação de poder e à dominação que existe no relacionamento afetivo, geralmente o agressor detém, em relação à mulher que ele agride, a força física e o poder econômico, passando a manipulá-la, violá-la e agredi-la psicologicamente, moralmente e fisicamente.

\section{A PREVENÇÃO E A PUNIÇÃO DA VIOLÊNCIA DOMÉSTICA PRATICADA CONTRA A MULHER, CONSIDERADO UM DIREITO FUNDAMENTAL, E A IMPORTÂNCIA DA LEI MARIA DA PENHA}


A Constituição Federal de 1988 garantiu tratamento isonômico entre os homens e as mulheres e, em seu art. $5^{\circ}$, inciso I, afirmando que "homens e mulheres são iguais em direitos e obrigações, nos termos desta Constituição".

Observa Dias (2007, p. 31) que apesar de todos os avanços, da equiparação entre o homem e a mulher feita pela Constituição Federal de 1988, a ideologia patriarcal ainda subsiste e se sobrepõe a todas essas conquistas. A desigualdade sociocultural é uma das razões da discriminação feminina, e, principalmente, de sua dominação pelos homens que se consideram como sendo seres superiores e mais fortes. Eles passam a considerar o corpo da mulher, como também sua vontade, como sendo sua propriedade.

Cavalcanti (2007, p. 31) ressalta que o preconceito e a discriminação estão evidentes em dados socioeconômicos que indicam que as mulheres, principalmente as negras, são discriminadas no mercado de trabalho, quando não conseguem empregos ou ocupam cargos secundários, apesar de serem qualificadas; ou quando recebem salários inferiores, quando ocupam os mesmos cargos que os homens ou as mulheres brancas.

Especificamente, quanto à igualdade de gêneros, sob o impacto da atuação do movimento de mulheres, a Conferência dos Direitos Humanos de Viena de 1993 (que tanto inspirou a Convenção de Belém do Pará) redefiniu as fronteiras entre o espaço público e a esfera privada, superando a divisão que até então caracterizava as teorias clássicas do Direito. A partir dessa reconfiguração, os abusos que têm lugar na esfera privada - como o estupro e a violência doméstica - passam a ser interpretados como crimes contra os direitos da pessoa humana.

Wolkmer (2003, p. 12) destaca que são direitos de terceira geração os direitos de gênero, ou seja, dignidade da mulher, subjetividade feminina, os direitos da criança e do adolescente como também os direitos dos idosos.

Observa-se que, com relação aos direitos de terceira geração, em razão de terem uma titularidade coletiva, há necessidade de criação, no âmbito do Direito, de novas técnicas que promovam sua garantia e proteção. Ritt (2002, p. 58) destaca que, ainda que haja restrições quanto à positivação desses direitos, internacionalmente, através de um grande número de tratados, ainda que de forma tímida, tal já começa a ocorrer.

O Estado está juridicamente comprometido a proteger a família e a cumprir sua função preventiva no que se refere à prática da violência doméstica. Por isso, deve ser chamado a redimensionar o problema sob a ótica dos direitos humanos e fundamentais. Souza 
(2007, p. 41) lembra que é necessário observar que em relação à mulher há a existência de Direitos Humanos que são consagrados por meio de diversos Tratados e Convenções Internacionais, esses, por sua vez, ratificados e integrados ao Sistema Jurídico Brasileiro, qual sejam: Convenção sobre a Eliminação de Todas as Formas de Discriminação contra a Mulher, que foi ratificada em 1994, e a Convenção Interamericana para Prevenir, Punir e Erradicar a Violência contra a Mulher - "Convenção de Belém do Pará", que foi ratificada em 1995.

Como observa Porto (2007, p. 20), deve-se partir do reconhecimento sociológico de que não há uma igualdade entre homens e mulheres, ou seja, essa isonomia é apenas formal, explícita no princípio constitucional da igualdade, repetida muitas vezes em legislação ordinária, mas, de fato, não se transferiu essa "igualdade" ou "isonomia" dos textos legais para a vida cotidiana.

Foram inúmeras conquistas legais alcançadas pelas mulheres, por meio de movimentos feministas, principalmente, através dos tempos: como por exemplo, o direito a terem educação, ao sufrágio no Brasil, e, com a Constituição de 1988, previsão tratamento isonômico com relação aos homens, em aspectos relacionados ao direito de família e, também aprovação de lei com relação à prevenção e ao combate à violência doméstica.

Com relação à educação, ensina Harner (2003. p. 76-78) que foi em 1827 que surgiu no Brasil a primeira legislação referente à educação feminina. A lei admitia meninas somente na escola elementar, mas não nas instituições de ensino superior. A ênfase da educação permanecia na costura e não na leitura e escrita. Os pais desejavam, e a lei ordenava, que as escolas femininas enfatizassem as prendas domésticas que não eram ensinadas aos meninos. Poucas escolas públicas eram construídas para as meninas e os baixos salários, que eram pagos aos professores, também deixavam a educação feminina pouco atraente. Em 1834, uma emenda constitucional, que era parte de um processo de descentralização, conferia às assembleias provinciais o poder de implantar e de regulamentar escolas públicas primárias, mantinha a legislação que regia a educação superior sob a responsabilidade do governo central. De forma indireta, significou que o governo central abandonava a educação das meninas nas mãos de mulheres mal pagas e mal instruídas. E educação pública, na realidade agrária da época e escravocrata, tinha pouco apoio do empobrecido tesouro nacional.

O direito de voto tornou-se o foco da atividade feminista nos anos 20. As feministas brasileiras montaram uma excelente campanha sufragista que acabou atingindo seu objetivo 
em 1932, apenas uma década depois da fundação da Federação Brasileira pelo Progresso Feminino. As líderes femininas acreditavam que a chave das futuras conquistas estava no poder do voto. E, ao contrário do que ocorreu em outros países, buscavam unir-se ao sistema como participantes iguais, para assim melhorá-lo, e não para subvertê-lo. Líderes do movimento sufragista do Brasil encontraram-se com Getúlio Vargas e a sua concordância de que acontecesse o sufrágio feminino universal, foi decisiva. Em 24 de fevereiro de 1932 o novo Código deu amplo direito de voto às mulheres, sob as mesmas condições dadas aos homens, mas, analfabetos de ambos os sexos permaneciam sem poder votar. O Brasil tornouse o quarto país do hemisfério ocidental a garantir o voto às mulheres, logo depois do Canadá, dos Estados Unidos e do Equador. Destaca Harner (2003, p. 332-333) que a campanha sufragista no Brasil nunca se tornou um movimento de massas, mas, apesar disso, teve o mérito de se caracterizar por sua excelente organização, bem maior do que a maioria dos movimentos semelhantes que a seguiram na América Latina.

Com o voto, as mulheres não podiam ficar excluídas do processo político. Da mesma forma, sua base doméstica estabelecida permanecia firme. Nos anos 30, as mulheres instruídas do Brasil tinham alcançado o grau de instrução de participação que ambicionavam. Conseguiram acesso a respeitáveis posições profissionais assim como o direito ao voto. Sem ser radicais em seus objetivos, nem agressivas em suas táticas, as mulheres que queriam o direito ao sufrágio, queriam alguns dos direitos exercidos pelos homens de sua própria classe. Não desejavam revolucionar a sociedade ou reestruturar a família.

Dentre direitos alcançados ao longo o do tempo, e também com relação à aprovação de leis para a punição e à prevenção da violência doméstica, destaca-se, como principal, a Lei 11.340/2016, batizada de Lei Maria da Penha. A justificativa de sua aprovação, nas palavras de Maria Berenice Dias (2007, p. 13) é dolorosa, pois Maria da Penha Maia Fernandes foi mais uma das vítimas da violência doméstica no Brasil. Como muitas outras mulheres, ela reiteradamente denunciou as agressões que sofreu. Por duas vezes, seu marido, professor universitário e economista, tentou matá-la. Na primeira tentativa de homicídio, em 29 de maio de 1983, ele simulou um assalto fazendo o uso de uma espingarda. Como resultado, ela ficou tetraplégica. Após alguns dias, pouco depois de uma semana, na segunda tentativa de homicídio, buscou eletrocutá-la por meio de uma descarga elétrica enquanto ela tomava banho. 
Tais fatos aconteceram em Fortaleza, no Ceará, sendo que as investigações começaram em junho de 1983, mas a denúncia foi oferecida em setembro de 1994. Em 1991, o ex-marido de Maria da Penha, foi condenado pelo Tribunal do Júri a oito anos de prisão. Além de recorrer em liberdade, um ano após, teve seu julgamento anulado. Em 1996 foi levado a novo julgamento, onde foi-lhe imposta a pena de dez anos e seis meses após os fatos. Mais uma vez recorreu em liberdade e somente dezenove anos e seis meses após os fatos, no ano de 2002 é que ele foi preso cumprindo apenas dois anos de prisão.

Destaca Dias (2007, p. 14) que a repercussão da história da Maria da Penha foi tão grande, que o Centro pela Justiça e o Direito Internacional - CEJIL e o Comitê Latino Americano e do Caribe para a Defesa dos Direitos da Mulher - CLADEM - formalizaram denúncia à Comissão Interamericana de Direitos Humanos da organização dos Estados Americanos. A Comissão solicitou, por quatro vezes, informações ao governo brasileiro, mas nunca recebeu nenhuma resposta. O Brasil foi condenado internacionalmente em 2001. O Relatório da OEA, além de impor o pagamento de indenização no valor de 20 mil dólares em favor da Maria da Penha, responsabilizou o Estado brasileiro por negligência e omissão em relação à violência doméstica, recomendando a adoção de várias medidas, dentre elas as de simplificar os procedimentos judiciais penais a fim de que possa ser reduzido o tempo processual. Foi em face da pressão sofrida por parte da OEA que o Brasil cumpriu as convenções e tratados internacionais que qual é signatário.

A Lei Maria da Penha se destina a coibir e prevenir a violência doméstica e familiar contra a mulher. Dispondo, também, sobre a criação dos Juizados de Violência Doméstica e Familiar contra a mulher. Estabelece medidas de assistência e proteção às mulheres que estejam em situação de violência doméstica e familiar. O legislador optou, através desta lei, em coibir a vergonhosa e reiterada prática de violência contra a mulher, no âmbito doméstico e familiar. (SOUZA, 2007, p. 34-35)

Os avanços trazidos pela Lei Maria da Penha, são muito significativos. Ensina Dias (2007, p. 25-26) que uma das grandes novidades foi a criação dos Juizados da Violência Doméstica e familiar contra a Mulher - JVDFMs, com competência cível e criminal. Devolvida à autoridade policial a prerrogativa investigatória, cabe a ele instaurar o inquérito. A mulher, que é vítima da violência doméstica deverá sempre estar acompanhada de advogado, tanto na fase policial como na judicial e é garantido a ela o acesso aos serviços da Defensoria Pública e da Assistência Judiciária Gratuita. Ela não pode ser portadora da 
notificação ou da intimação do agressor. Também deverá a vítima ser pessoalmente cientificada, quando o agressor for preso e ou liberado da prisão, sem prejuízo da intimação do seu procurador constituído ou do defensor público.

Outra inovação, muito importante é que, o juiz deverá adotar medidas que façam cessar a violência, como por exemplo: determinar o afastamento do agressor do lar, impedi-lo que se aproxime da casa, vedar o seu contato com a família. Também tem o dever de encaminhar a mulher e os filhos a abrigos seguros, garantindo-lhe que seja mantido o seu vínculo de emprego. Além disso, o juiz poderá também decretar a separação de corpos, fixar alimentos, bem como adotar outras medidas como: suspender a procuração outorgada ao agressor e anular a venda de bens e comuns.

A Lei Maria da Penha também proíbe a aplicação de pena pecuniária, multa ou entrega de cesta básica e permite a prisão preventiva do agressor. E, o no último dispositivo a Lei permite que o juiz determine que o agressor compareça, de forma obrigatória, a programas de recuperação e reeducação.

Sem dúvida a Lei Maria da Penha é, atualmente, a mais importante Lei que dispõe a mulher, que é vítima da violência doméstica, para garantir sua segurança e buscar a punição do agressor. Daí a importância do projeto de extensão, que será a seguir apresentado, de como acontecem os esclarecimentos às vítimas de todos os seus direitos, e como devem ser feitos encaminhamentos para o Poder Judiciário e outros órgãos públicos, como objetivo principal, de fazer cessar a violência doméstica a atingir também a punição do agressor.

\section{ALGUMAS CONSIDERAÇÕES REFERENTES AO PROJETO DE EXTENSÃO “ENFRENTAMENTO DA VIOLÊNCIA DOMÉSTICA E FAMILIAR: DIREITOS E GARANTIAS DA MULHER AGREDIDA”- DESENVOLVIDO PELA UNISC NA COMUNIDADE DE SANTA CRUZ DO SUL - RS E EM MONTENEGRO - RS}

Especificamente no que tange à violência cometida contra a mulher, verificou-se a comprovação por meio de estatísticas apresentadas pelas ONGs e por órgãos públicos, e também quando se faz uma observação da atividade policial e forense na qual a violência doméstica ocupa um grande espaço. Em recente notícia jornalística (ALVES, 2019, https://observatorio3setor.org.br), ressalta-se que "em 6 meses, 35 mil mulheres foram vítimas de violência doméstica". Observa-se que a Central de Atendimento à Mulher (Ligue 
180) recebeu 92.663 denúncias de violações contra mulheres em 2018, em todo o Brasil. Os dados foram divulgados pelo Ministério da Mulher, da Família e dos Direitos Humanos (MDH). Nos seis primeiros meses deste ano, o canal recebeu 46.510 denúncias. Isso representa um aumento de 10,93\% em relação ao mesmo período do ano anterior. Deste total, 35.769 das denúncias foram sobre violência doméstica e familiar. No ano passado, o Sistema Integrado de Atendimento à Mulher registrou 62.485 denúncias de violência doméstica e familiar, 12.878 de ameaças, 3.209 de violência psicológica, 3.065 de cárcere privado e 2.317 de violência sexual. Ainda, foram registradas 2.075 tentativas de feminicídio e 63 casos de feminicídio.

Em outra notícia jornalística, publicizada na web, (HEURICH, 2019, <https://g1.globo.com>) aborda o número de feminicídios no Rio Grande do Sul. Conforme notícia, o número de feminicídios em maio de 2019 é o maior registrado no ano no Rio Grande do Sul, de acordo com dados divulgados pela Secretaria da Segurança Pública (SSP). Treze mulheres foram assassinadas no Estado em contextos discriminatórios, mais do que o dobro em relação ao mês anterior. O indicador também assusta se comparado aos anos anteriores. A reportagem ressalta que: foi o Maio com mais casos de feminicídio desde 2012, quando a Polícia Civil gaúcha passou a contabilizar os homicídios de mulheres separadamente. A quantidade desse tipo de crime aumentou $30 \%$ na comparação com maio de 2018 e $333 \%$ em relação a maio de 2017 . Trouxe, também, a reportagem que a grande maioria da violência contra a mulher é dentro de um contexto de violência doméstica.

A Secretaria Estadual de Segurança Pública apresenta, anualmente, os Indicadores da Violência Contra a Mulher - Lei Maria da Penha, em que é possível visualizar o número de mulheres vítimas de ameaça, lesão corporal, estupro, feminicídio consumado e feminicídio tentado por mês. A pesquisa mostra o número de ocorrências: Em Santa Cruz do Sul - 2020 (até o mês de março): Ameaça: 119; Lesão Corporal: 55; Estupro: 03. E em Montenegro 2020 (até o mês de março): ameaça: 81; lesão Corporal: 36; Estupro: 02; feminicídio tentado: $01 .^{\dagger}$

\footnotetext{
${ }^{\dagger}$ Secretaria da Segurança Pública, Observatório Estadual de Segurança Pública. Indicadores da Violência Contra a Mulher - Lei Maria da Penha. Disponível em: 〈https://ssp.rs.gov.br/indicadores-da-violencia-contra-amulher>. Acesso em: 30. Abr. 2020.
} 
Com relação à cidade de Montenegro, em recente evento relacionado à violência doméstica praticada contra a mulher, a delegada Cleusa Spinato, titular da Delegacia da Mulher no Vale do Caí, lembrou que a região tem um dos maiores índices de violência contra a mulher no Estado (BAPTISTA, 2019, <https://fatonovo.com.br>).

Outra notícia jornalística trouxe que, conforme dados da Secretaria de Segurança Pública do Rio Grande do Sul, entre 2012 e o primeiro semestre de 2017, a região do Vale do Caí, da qual a cidade de Montenegro faz parte, registrou um total de setenta e quatro feminicídios o que correspondeu a quatorze por cento dos casos ocorridos no Rio Grande do Sul no período (SGARBI, 2017 <https://www.jornalnh.com.br/>).

Foi justamente por meio da constatação de registro de muitos casos envolvendo violência doméstica e familiar contra a mulher, nas cidades de Santa Cruz do Sul - RS e suas respectivas regiões é que ficou evidente a necessidade de efetivação do projeto de extensão, pela UNISC, que é uma instituição comunitária, para se alcançar, auxiliando, ajudando as vítimas da violência doméstica.

São muitas as situações que implicam a aplicação da Lei Maria da Penha às vítimas deste tipo de violência, e elas, principalmente pela condição de vulnerabilidade e baixa escolaridade, não possuem o conhecimento da aplicação da própria Lei, seus institutos, suas peculiaridades, seus direitos e garantias, principalmente diante da possibilidade ou não de representação contra o agressor.

O que se constata é que diante da própria violência doméstica, a vítima ainda não tem conhecimento dos direitos e das garantias que a lei determina. Assim, faz-se necessário um atendimento humanista, com privacidade, esclarecendo, fazendo a devida orientação jurídica, quanto aos direitos da mulher agredida, que estão previstos na Constituição Federal, Lei Maria da Penha, e nas demais determinações infraconstitucionais, como questões de direitos de família, separação, alimentos, guarda dos filhos, tanto a legislação estadual como municipal. Para isso é feito o atendimento diário, em dois turnos, no interior da Delegacia Especializada no Atendimento à Mulher, de ambas as cidades.

A atividade das bolsistas de extensão do projeto consiste no auxílio às vítimas, atendendo a vítima que chega à delegacia, após a ocorrência de violência, ameaças e busca atendimento neste órgão público. Geralmente muito fragilizada e sem informações de seus direitos ou de medidas de proteção que legalmente dispõe para sua proteção. Da mesma forma, para as mulheres que já possuem procedimentos em andamento na delegacia, as 
bolsistas tentam auxiliá-las por meio de contato telefônico, com a intenção de verificar a atual situação delas, para também orientar acerca da continuidade do procedimento instaurado.

Então, o projeto também proporciona uma melhor interação entre a sociedade e a Universidade, além do que proporciona aos alunos do Curso de Direito de Santa Cruz e Montenegro, mais um local para colocar em prática seus conhecimentos.

Também é disponibilizado à vítima, após realizado o atendimento, uma avaliação do atendimento por meio de uma pesquisa de opinião. São perguntas objetivas e de fácil compreensão, que uma vez respondidas, servirão como base para se buscar sempre o melhoramento do atendimento. Responder este questionário é optativo pela vítima ou seu familiar, não está vinculado ao atendimento. Este preenchimento poderá ser feito com ajuda de um aluno ou familiar, principalmente para as vítimas que sejam analfabetas, apresentem problemas de visão ou de audição.

Observa-se que as ocorrências mais frequentes são o delito de ameaça, seguido de lesão corporal. Nota-se que as questões culturais como: machismo, patriarcalismo, dependência financeira, entre outros tipos de subjugação do gênero feminino ainda são fatores determinantes nos casos de violência doméstica.

\section{A IMPORTÂNCIA DA EXTENSÃO UNIVERSITÁRIA PARA A FORMAÇÃO PRÁTICA E HUMANISTA DOS ESTUDANTES DO CURSO DE DIREITO}

Encaminhando-se para o final do presente artigo, e as devidas considerações finais, destacamos a importância da extensão universitária, que é a ação da Universidade junto à comunidade ela está inserida. O poder que a educação tem em transformar a sociedade, de forma mais justa, está ligada, também, à extensão universitária, mostra-se como possibilidade de formar alunos com uma visão mais humanista uma vez que a educação tem poder de transformação social.

A educação possui poder na construção de sociedades mais justas, fraternas e éticas. Como argumenta Hugo Espínola (2020, 104-105) ela é ferramenta determinante para a evolução dos povos rumo aos valores democráticos e aos relacionados com os direitos 
humanos. No âmbito da justiça social, moral e política, baseada na igualdade de direitos e na solidariedade coletiva, inexiste avanço sem a promoção de uma educação inclusiva, humanizadora e integrativa, para todos e com a atuação de todos. Destaca o referido que, pode-se afirmar que sem educação não há civilização nem prosperidade.

E, também, podemos citar ao entendimento atual da Unesco, citada por Andrade (2018, p. 176) que nesta perspectiva de educação integral para o desenvolvimento humano, por meio do conceito de cidadania global, postula princípios curriculares (expectativas de aprendizagem) para orientar as práticas educacionais nessa finalidade. Ela defende que a educação deve garantir o desenvolvimento de todos, como também de cada um, na perspectiva de uma multidimensionalidade cognitiva, sócio-emocional e comportamental.

Ideias que adquiriram um status oficial ao serem compartilhadas pela totalidade das instâncias internacionais que têm competências no campo da educação, como a ONU, a UNESCO e a OCDE, consideram que a função de educação é justamente de proporcional uma formação integral da pessoa, para que esta seja capaz de responder aos problemas que a vida propõe. $\mathrm{O}$ ensino deve ser para todos, independentemente de suas possibilidades profissionais. Formar em todas as suas possibilidades profissionais. Formar em todas as capacidades do ser humano, com a finalidade de poder responder aos problemas que a vida apresenta. E, ao mesmo tempo, observa-se ou, conforme destaca Zabala (2010, p. 21-23) a incapacidade de boa parte dos cidadãos escolarizados para saber utilizar os conhecimentos que, teoricamente, possuem, ou que foram apreendidos, em seu tempo escolar, em situações ou problemas reais, sejam cotidianos ou profissionais. Observa o referido, defendendo a necessidade de revisar o caráter dessas aprendizagens, devido a desconexão entre a teoria e prática.

Daí, destacamos a importância da extensão universitária, que também está no fato de que a busca e o contato com a realidade profissional aumentam a motivação, a criatividade, a inovação e a cientificidade para estudar os conteúdos quem envolvem a proposta, colocando o estudante como protagonista de sua aprendizagem.(LIMA, 2020, p. 46)

Nas palavras de Gatto (2019, p. 97) qualquer que seja a concepção de educação, ela deve fazer do aluno um ser único, não conformista e que tenha preparo, ou seja, espírito para enfrentar grandes desafios, que lhe traga valores que vão servir para guiar esta pessoa por toda a sua vida.

A extensão propicia novos aprendizados, porque com relação aos estudantes, pois eles constroem seu entendimento participando efetivamente da própria aprendizagem, 
mediante a experimentação, a pesquisa em grupo, o estímulo à dúvida, desenvolvimento do raciocínio, com reflexão do realmente aprender. (LIMA, 2020, p. 40)

A extensão universitária possibilita o compartilhamento, com as pessoas, com o público externo da universidade, do conhecimento que foi adquirido através do ensino e pesquisa desenvolvidos na instituição. Ocorre uma articulação do conhecimento científico, com as necessidades que a comunidade apresenta e onde ela está inserida. Desta forma, a universidade interage com a comunidade e colabora para a transformação social, garantindo valores democráticos de igualdade de direitos, respeito à pessoa e sustentabilidade ambiental e social. (UFES, 2013, http://www.proex.ufes.br)

A universidade, através da extensão, influencia e também é influenciada pela comunidade, possibilitando uma troca de valores entre ambas. A extensão universitária deve acontecer sempre como em uma via de duas mãos, ou seja, a Universidade leva conhecimentos e assistência à comunidade, ao mesmo tempo em que aprende com a realidade dessas comunidades.

Como observa Heitor Facini (2017, <https://www.kuadro.com.br>,) a extensão universitária faz parte do chamado tripé educacional junto com pesquisa e o com as atividades de ensino. Sua principal função é a de conectar as universidades com as comunidades em que estão inseridas, desenvolvendo projetos e as beneficiando diretamente. Ressalta o referido que a vida de um universitário não se resume somente ao que ele aprende em sala de aula, mas que a boa graduação é aquela onde o aluno tem acesso a outras iniciativas, dentre elas, a mais importante extraclasse é a extensão universitária. A extensão dá a oportunidade de o aluno explorar e desenvolver na prática o que aprendeu no curso universitário. Sendo que na extensão o contato com a comunidade é direto, pois o aluno extensionista acaba assumindo a responsabilidade como se estivesse diante de qualquer outro trabalho e atua, como diz o referido "fora dos muros da Universidade" o que trará uma experiência curricular enriquecedora e significativa em seu campo de atuação.

Ela possibilita a formação do profissional cidadão e se credencia, cada vez mais, junto à sociedade como espaço privilegiado de produção do conhecimento significativo para a superação das desigualdades sociais existentes. Fornece de subsídios para o aprimoramento curricular e criação de novos cursos. O mais importante é que ela possibilita a integração entre universidade-comunidade, daí a comunidade universitária poderá conhecer a 
problemática nacional e atuar na busca de soluções plausíveis, dentre outras qualidades ressaltadas. (SCHEIDEMANTEL, 2004, https://www.ufmg.br)

Mendonça e Silva (2002) pontuam que poucos são os que têm acesso direto aos conhecimentos gerados na universidade e que a extensão universitária é imprescindível para a democratização do acesso a esses conhecimentos, assim como para o redimensionamento da função social da própria universidade. Os referidos autores também ressaltam que uma das principais funções sociais da Universidade é a de contribuir na busca de soluções para os graves problemas sociais da população, formulando políticas públicas participativas e emancipadoras. A extensão, portanto, é indispensável na formação do aluno, na qualificação do professor e no intercâmbio com a sociedade. A qualidade e o sucesso dos profissionais formados pelas universidades dependem, diretamente, do nível de desenvolvimento, equilíbrio e harmonia entre essas três áreas da Universidade.

Analisou-se a fins de exemplo de extensão comunitária o projeto desenvolvido pela Universidade de Santa Cruz do Sul/ (UNISC/RS) "Enfrentamento da violência doméstica e familiar - Direitos e garantias legais da Mulher agredida", desenvolvido em parceria com a Delegacia Especializada no Atendimento à Mulher, nas cidades gaúchas de Santa Cruz e Montenegro. Ressaltou-se que ele tem como principal objetivo prestar assistência às vítimas de violência doméstica e familiar, fornecendo orientação sobre seus direitos previstos na Constituição Federal, Lei Maria da Penha e demais legislações Infraconstitucionais. Objetivase realizar os atendimentos com privacidade e de forma humanizada, pelo fato de que a mulher chega à delegacia sem informações sobre seus direitos, não sabe a quem recorrer e está muito fragilizada devido à violência que está sofrendo. O projeto conta com duas bolsistas estudantes do curso de graduação em Direito, da UNISC, em cada campus, o que é muito importante para o crescimento profissional e humano destes alunos.

São muitos pontos positivos que estão sendo alcançados, com atendimento das vítimas e esclarecimento de seus direitos. Busca-se a inserção comunitária da Universidade, por meio deste projeto humanista e que serve para mudar esta triste realidade.

Observa-se que é a primeira edição do projeto em Montenegro, mas em Santa Cruz do Sul, já tem sete anos de duração, atendendo com muita responsabilidade as mulheres que são agredidas. E, em Montenegro os resultados já se mostram muito positivos, com atendimento de várias vítimas, orientação e encaminhamentos. 
O projeto também proporciona uma melhor interação entre a sociedade e a Universidade, além do que proporciona aos alunos do Curso de Direito de Santa Cruz e de Montenegro, mais um local para colocar em prática seus conhecimentos.

E, finalmente, concordamos com Lima e demais (http://www.editorarealize.com.br) que a extensão é meio facilitador e promissor pelo qual a Universidade tem a oportunidade de levar até a comunidade os conhecimentos dos quais é detentora, ou seja, é a forma pela qual ela encontra de democratizar o conhecimento e fazer com que este chegue até àqueles que não são universitários.

\section{CONCLUSÕES}

O presente artigo responde ao problema de pesquisa proposto: destacando a importância da extensão universitária na formação prática e humanista dos alunos do curso de Direito caracterizando-se em uma oportunidade para aplicação dos ensinamentos adquiridos durante a graduação em situações reais que lhes são apresentadas, buscando soluções, dandose conta dos problemas sociais e adquirindo uma formação mais humanista, no trato com estas pessoas e problemas sociais. É por meio da extensão que vemos a verdadeira inserção comunitária da universidade.

$\mathrm{O}$ presente artigo foi desenvolvido em quatro partes. Na primeira, pretendeu-se abordar a violência doméstica com definições e índices atuais. Observa-se que a violência praticada contra a mulher ao longo do tempo está intimamente ligada aos aspectos culturais como machismo e formação de sociedade patriarcal. A subjugação da mulher através da violência caracteriza-se em reflexo desta cultura machista, da relação de dependência econômica e da pouca escolaridade que potencializam esta triste realidade de violência.

$\mathrm{Na}$ segunda parte, o objetivo foi o de analisar alguns aspectos referentes à proteção legal que a mulher tem no Brasil, legislação constitucional que trata deste assunto, e, principalmente a Lei Maria da Penha, considerada a mais importante no combate à violência doméstica praticada contra a mulher.

No terceiro tópico, a explicação de como é desenvolvido, em Santa Cruz do Sul e em Montenegro - RS, o projeto de extensão, pela UNISC - Universidade de Santa Cruz do Sul/RS: "Enfrentamento da violência doméstica e familiar - Direitos e garantias legais da 
Mulher agredida”, desenvolvido em parceria com a Delegacia Especializada no Atendimento à Mulher de cada uma destas cidades.

Ressaltou-se que ele tem como principal objetivo prestar assistência às vítimas de violência doméstica e familiar, fornecendo orientação sobre seus direitos previstos na Constituição Federal, Lei Maria da Penha e demais legislações Infraconstitucionais, objetivando realizar os atendimentos com privacidade e de forma humanizada, pelo fato de que a mulher chega à delegacia sem informações sobre seus direitos, não sabe a quem recorrer e está muito fragilizada devido à violência que está sofrendo.

Demonstrou-se que o referido projeto conta com duas bolsistas, estudantes do curso de graduação em Direito, na UNISC, o que é muito importante para o crescimento profissional e humano destes alunos. São muitos pontos positivos que estão sendo alcançados, com atendimento das vítimas e esclarecimento de seus direitos. Busca-se a inserção comunitária da Universidade, através deste projeto humanista e que serve para mudar esta triste realidade.

Finalmente, respondendo o problema de nossa pesquisa e alcançando o objetivo geral, destacamos a importância da extensão universitária na formação humanista de nossos alunos, uma vez que estão diante de problemas sociais práticos e terão oportunidade de conjugar ensinamentos teóricos com situações práticas apresentadas.

Esta experiência é excelente para o desenvolvimento e crescimento pessoal e profissional dos alunos do curso de Direito. A extensão significa que a Universidade está atuando além dos seus muros, além da sala de aula. A inserção comunitária é outro ponto muito positivo da extensão universitária: os alunos vão estar ajudando a resolver problemas que a comunidade enfrenta, comunidade esta onde a Universidade em que estudam, está inserida. Ou seja, a extensão é meio facilitador e também promissor onde a Universidade tem a oportunidade de levar para a comunidade os conhecimentos que ela possui.

\section{REFERÊNCIAS}

ALVES, Isabela. Em 6 meses, 35 mil mulheres foram vítimas de violência doméstica. Disponível em: https://observatorio3setor.org.br/noticias/em-6-meses-35-mil-mulheresforam-vitimas-de-violencia-domestica/. Acesso em: 02 set. 2019. 
ANDRADE, Júlia Pinheiro.; SARTORI, Juliana. O professor autor e experiências significativas na educação do século XXI: estratégias ativas baseadas na metodologia de contextualização da aprendizagem. In: BACICH, Lilian.; MORAN, José. (Org.). Metodologias ativas para uma educação inovadora: uma abordagem teórica-prática. Porto Alegre: Penso, 2018.

ARENDT, Hannah. Sobre a violência. Rio de Janeiro: Relume Dumará, 1994.

BAPTISTA, Guilherme. Mais garantias II: Quebrando o silêncio. 2019. Disponível em: < https://fatonovo.com.br/eventos/mais-garantias-ii-quebrando-o-silencio-destacou-medidas-deprotecao-as-mulheres/>. Acesso em 04 set. 2019.

CAVALCANTI, Stela Valéria Soares de Farias. Violência Doméstica: análise da lei "Maria da Penha", nº 11.340/06. Salvador, BA: Edições PODIVM, 2007.

DIAS, Maria Berenice. A Lei Maria da Penha na justiça: a efetividade da Lei 11.340/2006 de combate à violência doméstica e familiar contra a mulher. São Paulo: Editora Revista dos Tribunais, 2007.

ESPÍNOLA, Hugo. Desenvolvimento de competências pessoais e profissionais em vivências de sociocracia. In: DEBALD, Blasius. (org.). Metodologias ativas no ensino superior: o protagonismo do aluno. Porto Alegre: Penso, 2020, p. 104-105.

FACINI, Heitor. Qual a importância da extensão universitária? 2017. Disponível em: <https://www.kuadro.com.br/posts/qual-a-importancia-da-extensao-universitaria/>. Acesso em: 29/04/2020.

FRANCO, Luiza. Violência contra a mulher: novos dados mostram que 'não há lugar seguro no Brasil'. Disponível em: https://www.bbc.com/portuguese/brasil-47365503. Acesso em: 02 set. 2019.

GATTO, John Taylor. Emburrecimento programado: o currículo oculto da escolarização obrigatória. Trad. Leonardo Araújo. Campinas/SP, CEDET - Centro de Desenvolvimento Profissional e Tecnológico, 2019.

HAHNER, June Edith. Emancipação do sexo feminino: a luta pelos direitos da mulher no Brasil. 1850-1940. Florianópolis: Ed. Mulheres; Santa Cruz do Sul: EDUNISC, 2003.

HIRIGOYEN, Marie-France. A violência no casal: da coação psicológica à agressão física; tradução de Maria Helena Kühner - Rio de Janeiro: Bertrand Brasil, 2006.

HEURICH, Joyce. Número de feminicídios em maio de 2019 é o maior registrado no ano no $R S$, apontam dados da SSP. Disponível em: https://g1.globo.com/rs/rio-grande-dosul/noticia/2019/06/13/numero-de-feminicidios-em-maio-de-2019-e-o-maior-registrado-noano-no-rs-apontam-dados-da-ssp.ghtml. Acesso em: 02 set. 2019. 
LIMA, José Erlandro Cardoso de; SILVA, Ingrid Raquel Nóbrega da; NASCIMENTO NETO, Pedro Francisco do; PEREIRA, Charlane Kelly Souto; BAKKE, Larissa Almeida. A importância da extensão universitária na formação profissional do curso de farmácia. In: II CONBRACIS: II Congresso Brasileiro de Ciências da Saúde. Disponível em: <http://www.editorarealize.com.br/revistas/conbracis/trabalhos/TRABALHO_EV071_MD1_ SA3_ID2191_14052017154833.pdf>. Acesso em: 30 abr. 2020.

LIMA, Maurícia Cristina de LIMA; CLAPIS, Maria José. Estudantes aprendem fazendo com significado. In: Metodologias ativas no ensino superior: o protagonismo do aluno. Organizador: Blasius Debald. Porto Alegre: Penso, 2020.

LINTZ, Sebastião. O crime, a violência e a pena. Campinas - SP. 1987.

MELLO, Adriana Ramos de. Aspectos gerais da lei. In: (Org.). Violência Doméstica e familiar contra a mulher. Comentários à Lei de Violência Doméstica e Familiar contra a mulher. Rio de Janeiro: Editora Lumen Juris, 2007.

MENDONÇA, S. G. L.; SILVA, P.S. Extensão Universitária: Uma nova relação com a administração pública. Extensão Universitária: ação comunitária em universidades brasileiras. São Paulo, v. 3, p. 29-44, 2002.

PORTO, Pedro Rui da Fontoura. Violência doméstica e familiar contra a mulher: Lei 11.340/06: análise crítica e sistêmica. Porto Alegre: Livraria do Advogado Editora, 2007.

RITT, Eduardo. O Ministério Público como instrumento de democracia e garantia constitucional. Porto Alegre: Livraria do Advogado, 2002.

SABADELL, Ana Lucia. Manual de Sociologia Jurídica: introdução a uma leitura externa do Direito. 3. ed. São Paulo: Revista dos Tribunais, 2005.

SCHEIDEMANTEL, Sheila Elisa; KLEIN, Ralf; TEIXEIRA, Civil Lúcia Inês; A Importância da Extensão Universitária: o Projeto Construir. In: Anais do $2^{\circ}$ Congresso Brasileiro de Extensão Universitária. Belo Horizonte, 2004. Disponível em: https://www.ufmg.br/congrext/Direitos/Direitos5.pdf. Acesso em: 30. Abr. 2020.

SGARBI, Karina. Preso por morte de jovem no Caí tinha condenação por tentativa de estupro. 2017. Disponível em:<https://www.jornalnh.com.br/_conteudo/2017/11/noticias/regiao/2206319-comcondenacao-anterior-por-tentativa-de-estupro-homem-e-preso-por-morte-de-jovem-nocai.html>. Acesso em 05 set. 2019.

SOARES, Bárbara Musumeci. Mulheres Invisíveis. Violência Conjugal e Novas Políticas de Segurança. Civilização Brasileira. Rio de Janeiro, 1999. 
SOUZA, Sérgio Ricardo. Comentários à Lei de Combate à violência contra a mulher.

Curitiba: Juruá, 2007.

UFES - UNIVERSIDADE FEDERAL DO ESPÍRITO SANTO. O que é extensão universitária? 2013. Disponível em: http://www.proex.ufes.br/o-que-\%C3\%A9extens\%C3\%A3o-universit\%C3\%A1ria. Acesso em: 29. Abr. 2020.

WOLKMER, Antonio Carlos. Introdução aos Fundamentos de uma teoria Geral dos 'Novos' Direitos. in: Wolkmer, Antonio Carlos e LEITE, José Rubens Morato (organizadores). Os 'Novos' Direitos no Brasil, Natureza e Perspectivas. São Paulo: Saraiva, 2003.

ZABALA, Antoni. ARNAU, Laia. Como aprender e ensinar competências. Porto Alegre: Artmed, 2010. 